Short paper and poster abstracts: $38^{\text {th }}$ Congress of the South African Society of Animal Science

\title{
Heritabilities of reproductive traits in a beef cattle herd using multitrait analysis
}

\author{
R.R. van der Westhuizen ${ }^{1}$, S.J.Schoeman ${ }^{1}$, G.F. Jordaan ${ }^{1}$ and J.B. van Wyk ${ }^{2}$ \\ ${ }^{1}$ Dept of Animal Science, University of Stellenbosch, P Bag X1, Matieland, 7602 \\ ${ }^{2}$ Dept of Animal Science, University of Orange Free State; P O Box 339,Bloemfontein, 9300
}

\section{Introduction}

Reproduction is a critically important aspect of overall efficiency in the livestock industry. However, reproduction is a complex process with many components. Several such components have been used as measures of reproductive performance. Calving interval (CI), calving rate, services per conception, age at first calving (AFC), days to calving and calving date (CD) are some of the components of the female "reproductive complex" that have been considered. Animal geneticists are beginning to explore the possibility of separating components of the female "reproductive complex" into subsets that are both relatively easy to measure and have higher heritabilities. CI has traditionally been the predominant measure of reproduction during the productive life of the animal, particularly in dairy cattle (Rege \& Famula, 1993). However, in beef operations, a relatively short breeding season is usually employed, so CI does not provide any additional information to CD and has lower repeatability and heritability (Bourdon \& Brinks, 1983). Beef cattle in South Africa, as in other countries, are mated during a limited breeding season. Bourdon \& Brinks (1983), Marshall et al. (1990) and MacGregor (1995) have found CI to be a biased measure of reproductive performance, due to it's negative association with $\mathrm{CD}$, which results in cows calving early having the longest CI. Direct selection for shorter CI could also result in indirect selection for later age at puberty, since cows with the shortest CI are often those whose calves were born late in calving seasons. Bourdon \& Brinks (1983), Buddenberg et al. (1990), Lòpez de Torre \& Brinks (1990), Marshall et al. (1990), and MacGregor (1995) suggested CD as the preferred reproduction measurement for numerous reasons applicable to a restricted breeding season. These include lower birth weights, reduced incidence of dystocia, higher weaning and yearling weights and higher reconception rates. The objectives of this study were to obtain heritabilities (for CI, CD and $\mathrm{AFC}$ ) and genetic correlations between these three traits.

\section{Materials and Methods}

Data used in this study were obtained from the multibreed synthetic beef cattle herd of the Johannesburg Metropolitan Council. After incomplete and biased records were removed, the data set contained 41849 observations of 13049 reproductive animals (dams and heifers) between 1979 and 1993. There were 25684 base animals in the pedigree file. Paterson $(1978 ; 1981)$ and MacGregor (1999) described the conditions under which these animals were kept and the management practices applied. Three traits were evaluated, namely calving interval (CI), calving date (CD), and age of first calving (AFC). CI was calculated as the interval in days between the subsequent and previous calving dates. $\mathrm{CD}$ was coded as the number of days from the onset of the calving season (1 June i.e.) until the dam calved. A penalty score for $C D$ was given to those animals that did not calf during a particular year. The cow having the highest calving date value in a year was identified and 21 days were added to her $\mathrm{CD}$ value. This value was assigned to all non-calvers for that particular year (Johnson \& Bunter (1996); MacGregor (1999)). A restricted maximum likelihood procedure with a multivariate animal model (using REML VCE 4.2.5 package of Groeneveld, 1998) was used to analyse the data. All traits were considered as a trait of the calf. The following effects were included in the model: year of birth (15 levels), month of birth (12 levels) and genotype (352 levels) as fixed effects and dam age as a covariate of CI and AFC. For CD, dam age was not significant in the initial analysis, therefore the rest of the effects were included in the operational model. Interactions were not significant in the initial analysis and therefore were ignored in the operational model.

\section{Results and Discussion}

Table 1 presents the heritabilities $\left(\mathrm{h}^{2}\right)$ and genetic correlations $\left(\mathrm{r}_{\mathrm{g}}\right)$. Above the diagonal are the genetic correlations between traits and on the diagonal are the heritabilities.

Table 1 Heritabilities and genetic correlations for reproductive traits

\begin{tabular}{lccc}
\hline & CI & CD & AFC \\
\hline CI & $0.016 \pm 0.002$ & $0.025 \pm 0.134$ & $0.468 \pm 0.089$ \\
CD & & $0.442 \pm 0.008$ & $0.600 \pm 0.019$ \\
AFC & & & $0.464 \pm 0.012$ \\
\hline
\end{tabular}


The heritability of CI corresponds with that found in the literature. Koots et al. (1994a) reported in his review $\mathrm{a} \mathrm{h}^{2}$ of 0.01 for CI (based on three estimates). López de Torre \& Brinks (1990) found $\mathrm{a} \mathrm{h}^{2}$ of 0.02 . The $\mathrm{h}^{2}$ for $\mathrm{CD}$, on the other hand, is unexpectedly high and may be biased. Koots et al. (1994a) reported a mean $\mathrm{h}^{2}$ of 0.08 for CD (based on seven estimates). However, Meacham \& Notter (1987), López de Torre \& Brinks (1990) and Rege \& Famula (1993) also obtained higher $\mathrm{h}^{2}$ values of 0.16, 0.17 and 0.16, respectively. Buddenberg et al. (1990), assigned a penalty score for $\mathrm{CD}$ to all non-calvers and obtained $\mathrm{a} \mathrm{h}^{2}$ value for $\mathrm{CD}$ in first calvers of 0.39 . Thus, the penalty score effect may be the reason for the higher $\mathrm{h}^{2}$ value for $\mathrm{CD}$ obtained in this study. Rege \& Famula (1993), found a low negative $r_{g}$ of -0.06 between CI and CD while Koots et al. (1994b) reported a $r_{g}$ of -0.83 between $\mathrm{CI}$ and CD. The $\mathrm{r}_{\mathrm{g}}$ between $\mathrm{CI}$ and $\mathrm{CD}$ in this study was not significant. AFC's $\mathrm{h}^{2}$ of 0.464 also corresponds with some of the $h^{2}$ values found in the literature. Kassab (1995), Singh et al. (1996) and Magana \& Segura (1997) obtained $h^{2}$ values of 0.46, 0.36 and 0.46, respectively for AFC. Singh et al. (1996) also found a $r_{g}$ of 0.68 between AFC and CI. The $h^{2}$ values for AFC and CD are both high and thus the preferred traits to use in a selection programme, rather than CI. The $\mathrm{r}_{\mathrm{g}}$ between $\mathrm{AFC}$ and $\mathrm{CI}$, and AFC and CD are moderate. Thus, selection for AFC could lead to an improvement in both CD and CI. Selection for CD could also lead to an improvement in AFC. AFC and CD are both traits that are easy to measure and both can be measured early in an animal's productive life. Selection for CD does have additional advantages over CI and AFC, as was discussed by Bourdon \& Brinks (1983), Buddenberg et al. (1990), Lòpez de Torre \& Brinks (1990), Marshall et al. (1990) and MacGregor (1995).

\section{Conclusions}

The $\mathrm{h}^{2}$ of CD and the $\mathrm{r}_{\mathrm{g}}$ between CD and AFC found in this study, and the additional advantages of CD, suggest that $\mathrm{CD}$ is the preferable trait to include in a reproduction selection programme rather than $\mathrm{AFC}$ and $\mathrm{CI}$.

\section{References}

Bourdon, R.M. \& Brinks, J.S., 1983. J. Anim. Sci. 57, 1412.

Buddenberg, B.J., et al., 1990. J. Anim. Sci. 68, 70.

Groeneveld, E., 1998. VCE4 Version 4.2.5 User's Guide and Reference Manual, Marience Germany.

Johnson, D.J. \& Bunter, K.L., 1996. Livest. Prod. Sci. 45, 13.

Kassab, M.S., 1995 Alexandria J. Agric. Res. 40, 65.

Koots, K.R. et al., 1994a. Anim. Breed. Abstr. 62, 309

Koots, K.R. et al., 1994b. Anim. Breed. Abstr. 62, 825

López de Torre, G. \& Brinks, J.S. (1990) J. Anim. Sci. 68, 2650.

MacGregor, R.G., 1995. J.S.Afr.vet.Assoc. 66, 234.

MacGregor, R.G., 1999. PhD Thesis. Univ. of Pretoria, Pretoria.

Magana, J.G. \& Segura, J.C., 1997. Trop. Anim. Health Prod. 29, 185.

Marshall, D.M. et al., 1990. J. Anim. Sci. 68, 1812.

Meacham, N.S. \& Notter, D.R., 1987. J. Anim. Sci. 64, 701.

Paterson, A.G., 1978. M.Sc.Agric. Thesis. Univ. of Pretoria, Pretoria.

Paterson, A.G., 1981. D.Sc.Agric. Thesis. Univ. of Pretoria, Pretoria.

Rege, J.E.O. \& Famula, T.R., 1993. Anim. Prod. 57, 385.

Singh, M. et al., 1996. Indian J. Anim. Res. 30, 65. 